\title{
¿POR QUÉ LA REPÚBLICA DE IRLANDA ESTÁ EN EL TOP DEL ÍNDICE DE ATRACTIVO REGULATORIO DE LOS PERMISOS MINEROS? UN ANÁLISIS DEL FACTOR TIEMPO'1
}

\section{WHY IS THE REPUBLIC OF IRELAND AT THE TOP OF THE REGULATORY ATTRACTIVENESS INDEX OF MINING PERMITS? AN ANALYSIS OF THE TIME FACTOR}

\author{
ENCARNACIÓN MONTOYA MARTÍN \\ Catedrática de Derecho Administrativo \\ Universidad de Sevilla \\ montoya@us.es
}

Fecha de recepción: 23 de mayo de 2020 / Fecha de aceptación: 10 de junio de 2020

RESUMEN: El estudio tiene por objeto el examen del marco regulatorio de los procedimientos de otorgamiento de los permisos mineros, teniendo en cuenta el índice de atractivo regulatorio o índice de percepción de políticas públicas y llevando a cabo un especial análisis del factor tiempo. La República de Irlanda es un pais atractivo desde el punto de vista regulatorio según las Encuestas anuales de empresas mineras del Instituto Fraser, lo que justifica el estudio del régimen jurídico de la minería y, en particular, de los permisos mineros en la Minerals Development Act de 2017, sus fortalezas y debilidades. El factor tiempo constituye una pieza clave de buena regulación de la actividad minera, por lo que se analiza detalladamente el plazo de resolución y notificación de los procedimientos de otorgamiento de los permisos mineros de los recursos de las Secciones C y D de la Ley de Minas de 1973, abogando por la necesidad de racionalizar el sistema y de acecar el plazo legal y el real como una de las piezas que contribuya a una buena regulación de la actividad minera.

\footnotetext{
${ }^{1}$ El presente estudio se ha realizado en el marco del Proyecto de Investigación DER2016-78393R "La minería extractiva en el siglo XXI: retos jurídicos y medioambientales", dirigido por los profesores Encarnación Montoya Martín y José Luis Rivero Ysern, de la Universidad de Sevilla.
} 
RESUM: L'estudi té per objecte l'examen de el marc regulador dels procediments d'atorgament dels permisos miners, tenint en compte l'índex d'atractiu regulador o índex de percepció de polítiques públiques i duent a terme un especial anàlisi de l'factor temps. La República d'Irlanda és una pais atractiu des del punt de vista regulatori segons les enquestes anuals d'empreses mineres de I'Institut Fraser el que justifica l'estudi de el règim jurídic de la mineria $i$, en particular, dels permisos miners en la Minerals Development Act de 2017, les seves fortaleses i debilitats. El factor temps constitueix una peça clau de bona regulació de l'activitat minera, per la qual cosa s'analitza detalladament el termini de resolució i notificació dels procediments d'atorgament dels permisos miners dels recursos de les seccions C i D de la Llei de mines de 1973, advocant per la necessitat de racionalitzar el sistema i de acecar el termini legal $i$ el real com una de les peces que contribueixi a una bona regulació de l'activitat minera.

ABSTRACT: The study aims to examine the regulatory framework of the procedures for granting mining permits, taking into account the regulatory attractiveness index or public policy perception index and carrying out a special analysis of the time factor. The Republic of Ireland is attractive from a regulatory point of view according to the Fraser Institute's Annual Surveys of Mining Companies, which justifies the study of the legal regime of mining and in particular of mining licences under the Minerals Development Act 2017, its strengths and weaknesses. The time factor is a key element of good regulation of mining activity, so the time period for resolution and notification of the procedures for granting mining permits for the resources of Sections $C$ and $D$ of the 1973 Mining Act is analyzed in detail, advocating the need to streamline the system and to bring the legal and actual time period into line as one of the elements contributing to good regulation of mining activity.

PALABRAS CLAVE: Minería - Permisos mineros - Buena regulación - Instituto Fraser - Índice de percepción de políticas pública - República de Irlanda - Factor tiempo, Ley de Minas, Secciones C y D, Procedimiento administrativo - EspañaCCAA. 
PARAULES CLAU: Mineria - Permisos miners - Bona regulació - Institut Fraser - Índex de percepció de polítiques pública - República d'Irlanda - Factor temps, Llei de mines, seccions C i D, Procediment administratiu - Espanya-CCAA.

KEY WORDS: Mining - Mining permits - Better regulation - Fraser Institute Public Policy Perception Index - Republic of Ireland - Time Factor - Mining Act - Sections C and D - Administrative procedure - Spain-Autonomous Regions

SUMARIO: I. Introducción. II. Las encuestas del instituto fraser sobre minería. 1. El Investment Attractiveness Index o índice de atractivo inversor (IAI). a. Clasificación de los países y regiones 2. En especial, el Policy Perception Index o índice de percepción de políticas públicas. a. Concepto. b. Las preguntas. c. Los resultados. d. La importancia de la tramitación de los procedimientos de otorgamiento de los permisos mineros: d.1. El factor tiempo. d.2. Otros indicadores: transparencia, seguridad jurídica y confianza. III. Régimen jurídico de la minería en la República de Irlanda: la minerals development act 2017. 1. La definición de minerales: ámbito de aplicación de la legislación minera. 2. Titularidad o propiedad de los recursos minerales. 3. Los permisos mineros. 4. Fortalezas y debilidades del régimen jurídico de los permisos mineros en Irlanda. IV. El margen de mejora regulatoria en la gestión de permisos mineros en España: un estudio del factor tiempo. V. Conclusión. VI. Bibilografía.

\section{INTRODUCCIÓN}

Las actividades extractivas son una fuente de innovación, empleo y riqueza, pero también causa de riesgos medioambientales. La UE tiene un alto grado de dependencia de las materias primas ${ }^{2}$ y de energía y de ahí la necesidad de la

\footnotetext{
2 Desde la Comunicación La iniciativa de las materias primas: cubrir necesidades fundamentales en Europa para generar crecimiento y Empleo, Bruselas, 4.11.2008 COM (2008) 699 final, la Comision está poniendo de manifiesto la importancia que las materias primas tienen para Europa, su modo de vida y su industria. Por su parte, en la Conferencia Europea de los Minerales, celebrada en Madrid en junio de 2010, evento promovido por las organizaciones empresariales de la industria extractiva española en colaboración con las europeas, se acordó como documento final la Declaración sobre las Materias Primas Minerales cuyos puntos claves son: promover una política de materias primas en el ámbito europeo que defina la estrategia adecuada para garantizar el abastecimiento de materias primas importadas, así como de suficiente acceso a sus propias materias primas naturales; que cada Estado miembro desarrolle las correspondientes políticas de materias primas en el ámbito nacional, regional y local, para garantizar un acceso adecuado a las materias primas geológicamente disponibles y, por último, que cada Estado miembro revise sus procedimientos de otorgamiento de permisos para acceder a los yacimientos de materias primas, habida cuenta que la mayoría de estos procedimientos son muy complejos y exigen mucho tiempo de dedicación. En definitiva, garantizar un otorgamiento de permisos eficiente y en plazos de tiempo definidos y razonables, concediendo períodos de explotación que justifiquen las importantes inversiones de capital requeridas.

Vease tambien la Comunicación de la Comisión al Parlamento Europeo, al Consejo, al Comité Económico y Social Europeo y al Comité de las Regiones "Abordar los retos de los mercados de productos básicos y de las materias primas" [COM (2011) 25 final de 2.2.2011]. La Comisión recuerda que ha elaborado directrices de aplicación del marco decisional de la Red Natura 2000 y que no hay ninguna exclusión automática de actividades extractoras en áreas de Natura 2000
} 
reducción de esta dependencia, armonizada con las exigencias de los más elevados estándares de sostenibilidad ambiental y del tránsito de la minería hacia la economía circular y más verde. Las materias primas, estén o no clasificadas como fundamentales ${ }^{3}$, son importantes para la economía europea, ya que están al inicio de las cadenas de valor manufactureras. Su disponibilidad puede cambiar rápidamente en consonancia con los flujos comerciales o la evolución de la política comercial, lo que pone de relieve la necesidad general de la diversificación del suministro y del aumento de los índices de reciclado de todas las materias primas.

No podemos olvidar que como ha puesto de relieve el Informe del Banco Mundial The Growing Role of Minerals and Metals for a Low Carbon Future Washington de junio 2017 el pacto en favor de la lucha contra el cambio climático conlleva "tecnologías limpias" que demandan un uso intensivo de materias primas y recursos minerales. Por ello, la minería ha de ser enfocada como un complemento y no como un sector opuesto y contrario a los principios de una economía cicular y sostenible en el futuro.

Dado el carácter estratégico de la minería, consideramos necesario analizar la actividad extractiva desde la perspectiva de la racionalización normativa o buena regulación ${ }^{4}$ del sector que contribuya a la mayor sostenibilidad social y

u otras conexas. Sobre ese tema véase el reciente y excelente estudio de CASADO CASADO, L. "Actividades extractivas y espacios naturales protegidos: la Red Natura 2000", en Minería extractiva, planificación territorial y urbanismo, MONTOYA MARTÍN, E. (Dir.), Tirant lo Blanch, Valencia págs. 26-102.

Puede consultarse el Informe de la Comisión al Parlamento europeo, al Consejo, al Comité Económico y Social europeo y al Comité de las Regiones sobre la aplicación de la Iniciativa de las Materias Primas / COM/2013/0442 final/.

${ }^{3}$ Vid la vigente Comunicación de la Comisión al Parlamento Europeo, al Consejo, al Comité Económico y Social Europeo, al Consejo y al Comité de las Regiones relativa a la lista de 2017 de veintisiete materias primas fundamentales para la UE (Bruselas, 13.9.2017 COM (2017) 490 final). La importancia económica y el riesgo del suministro continúan siendo los dos parámetros principales utilizados para determinar el carácter fundamental de una materia prima. Se trata de una lista actualizada resultado de una tercera evaluación.

${ }^{4}$ Principios de buena regulación que el ordenamiento jurídico español positivizó con carácter básico en la Ley 2/2011, de 4 de marzo, de Economía sostenible en los arts. 4-7, preceptos derogados y sustituidos por los arts.129 a 133 de la Ley 39/2015, de 1 de octubre, del Procedimiento Administrativo Común de las Administraciones Públicas (en adelante LPAC). Téngase en cuenta el FJ 7 de la STC 55/2018, de 24 de mayo, en el que se analizan los arts. impugnados del Título VI LPAC referidos a la «iniciativa legislativa y la potestad para dictar reglamentos y otras disposiciones", en concreto, los arts. $129,130,132$ y 133.

En cuanto a si el Estado puede legislar sobre principios de buena regulación que sean aplicables a los anteproyectos de normas autonómicas con rango de ley, la respuesta del TC es negativa puesto que: «el ejercicio de la iniciativa legislativa por parte de las Comunidades Autónomas, en general, y la elaboración de anteproyectos de ley, en particular, quedan por completo al margen 
medioambiental y a la eficacia y eficiencia de los yacimientos mineros a lo largo de todo el ciclo de vida (incluyendo la eliminación de residuos y la restauración de espacios) bajo el paradigma de la economía circular. Cabalmente, se trata de reivindicar la importancia de la regulación, es decir, del Derecho en la consecución del fomento de una minería sostenible como sector estratégico esencial, teniendo en cuenta que los recursos minerales se rigen por el principio de localización, factor indisponible para el hombre. Por el contrario, mejorar el marco normativo que contribuya a dotar de una regulación que combine el atractivo para el inversor, proporcionando más seguridad y transparencia, eliminando riesgos de externalidades que aumentan los riesgos debido a incertidumbres, duplicidades o corrupción, junto con elevados estándares de sostenibilidad ambiental y responsabilidad social es tarea en la que puede y debe invertirse a nivel europeo y por los diferentes Estados miembros que, disponiendo de tales recursos, quieran hacer de este sector estratégico motor de desarrollo. En esta línea, destaca el Informe "Legal framework for mineral extraction and permitting procedures for exploration and exploitation in the EU', Final report, Dirección General de Mercado Interior, Industria, Emprendimiento y Pymes Comisión Europea, Minpol, mayo 2017. Se trata de un estudio que proporciona información de la legislación aplicable a la minería no energética en los Estados y regiones de la UE, con el objeto de que la Comisión Europea tenga una visión más clara de la situación actual en materia de otorgamientos de permisos en los 28 Estados miembros ${ }^{5}$.

del art.149.1.18 CE en lo que se refiere tanto a las "bases del régimen jurídico de las Administraciones públicas" como al "procedimiento administrativo común"». Por tanto, los artículos cuestionados, invaden las competencias que las Comunidades Autónomas «tienen estatutariamente atribuidas en orden a organizarse y regular la elaboración de sus leyes».

En cambio, el FJ admite, a partir de lo ya declarado en la STC 91/2017, FJ 6, que las «bases» del art. 149.1.18 CE «pueden tener por objeto la elaboración de reglamentos por parte de las Comunidades Autónomas" y pueden incluir, respecto a éstos, principios de buena regulación, que no impiden su desarrollo por las Comunidades Autónomas o que éstas establezcan otros distintos, ni que regulen los procedimientos administrativos especiales conexos con sus competencias sustantivas.

${ }^{5}$ Este informe presenta los resultados del estudio del marco legal aplicable a la extracción de minerales en la UE, así como de los procedimientos de autorización para su exploración y explotación (MINLEX), que se desarrolló desde diciembre de 2015 hasta mayo de 2017. Pese al esfuerzo y lo postivo de la iniciativa, constituye sólo un primer paso, dede luego relevante, pero la información es incompleta y/o insuficiente. Creemos que se trata de un primer análisis, que precisa de mayor profundidad para ser capaz de poner de manifiesto las fortalezas y debilidades de cada país, así como los aspectos comunes que puedan ahormar los elementos básicos articuladores del denominador común de un régimen jurídico europeo de la minería no 
Por otra parte, las propuestas de mejora de la calidad normativa exigen previamente un estudio comparado del Derecho minero y de la legislación ambiental aplicable, así como de su interpretación y aplicación por las Administraciones responsables, no siempre fácil, dada su complejidad y especialización. Este trabajo se enmarca en esta línea y tiene por objeto el análisis del régimen de la minería en la República de Irlanda, en particular de los procedimientos de otorgamiento de los permisos mineros y de la incidencia del factor tiempo. Esta elección se debe a la posición privilegiada que la República de Irlanda ocupa en las encuestas sobre empresas mineras que lleva a cabo anualmente el Instituto Fraser desde 1997.

Por último, se llevará a cabo un análisis del factor tiempo en los procedimientos de otorgamiento de los permisos mineros en España, poniendo de manifiesto la diversidad de plazos legales existentes en las CCAA.

\section{LAS ENCUESTAS DEL INSTITUTO FRASER SOBRE MINERÍA}

Nuestro análisis toma como punto de partida las encuestas anuales que elabora el Instituto Fraser sobre minería ${ }^{6}$, en concreto, la más reciente Encuesta Anual de Empresas Mineras: 2019, de 25 de febrero de 20207, en la que se obtuvieron datos para evaluar 76 Estados y regiones. Cada año el número puede aumentar

energética, así como de propuestas de mejores prácticas para una futura armonización europea del régimen jurídico de la minería no energética.

6 Desde 1997, el Instituto Fraser ha llevado a cabo una encuesta anual de compañías y empresas mineras con el fin de evaluar cómo los recursos minerales y las políticas públicas con factores como la fiscalidad y la regulación inciden en las decisiones de los inversores en este sector. En definitiva, constituyen factores para incentivar o, por el contrario, desincentivar, las inversiones en el sector. Su objetivo es elaborar un informe que puedan usar los gobiernos con la finalidad de atraer inversiones en el sector minero.

7 ASHLEY STEDMAN, -JAIRO YUNIS-ELMIRA ALIAKBARI Annual Survey of Mining Companies, 2019, 25 febrero de 2020. La encuesta se envió a aproximadamente 2.400 empresas mineras en todo el mundo. Se realizó del 20 de agosto al 8 de noviembre de 2019. Las respuestas de la encuesta se han contabilizado para clasificar a las provincias, Estados y países según la medida en que los factores de la política pública alienten o desalienten la inversión minera. Este año se recibieron datos suficientes para evaluar 76 Estadosy regiones de todos los continentes, excepto de Asia y la Antártida. Para ser incluido en la encuestra y su análisis, han tenido en consderacion sólo los países y regiones respecto de los que han recibido al menos 5 respuestas de parte de las empresas encuestadas. En este sentido, hay que advertir que España, en virtud de este criterio, no ha sido incluida este año en la encuesta Fraser. 
o disminuir en función de que el sector minero crezca o se reduzca debido a los precios de los productos básicos y otros factores sectoriales.

\section{El Investment Attractiveness Index o índice de atractivo inversor (IAI)}

La clave de la encuesta Fraser es el punto de vista que adopta, y que entronca con el análisis económico, aplicado y empírico del Derecho ${ }^{8}$ complemento necesario para nuestro estudio. El Investment Attractiveness Index, es decir el índice de atractivo inversor ( $\mathrm{IAI}$ ) está compuesto por el índice de potencial minero que clasifica a los países y regiones por su atractivo geológico y el índice de percepción de políticas públicas, que mide los efectos de las regulaciones mineras sobre la exploración y explotación.

\section{a. Clasificación de los países y regiones ${ }^{9}$}

Este año, la lista de los diez países y regiones mejor clasificados son por orden: $1^{\circ}$. Australia Occidental, $2^{\circ}$ Finlandia que pasó al $2^{\circ}$ lugar después de estar en el $17^{\circ}$ el año anterior, $3^{\circ}$ Nevada, 4ำ Alaska, Portugal que mejoró del 46ำ lugar en

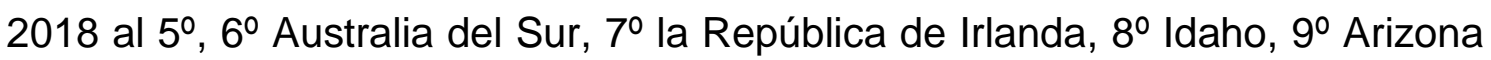
y $10^{\circ}$ Suecia.

\footnotetext{
${ }^{8}$ Véase DOMÉNECH PASCUAL, G. "Por qué y cómo hacer análisis económico del Derecho", $R A P, 195,2014$, págs. 99-133. Siguiendo a este autor, la utilización de la encuesta Fraser para el objeto de nuestra investigación puede considerarse como un análisis económico del Derecho, de carácter normativo, es decir, se ocupa de estudiar qué es lo que los agentes (el legislador, la Administración, los Tribunales, las partes contratantes, etc.), a la vista de las consecuencias esperadas de sus diversas alternativas de actuación, deberían hacer, qué decisiones deberían adoptar, qué normas deberían eventualmente establecer, a fin de maximizar la satisfacción de ciertas preferencias. Asimismo, se trata de un análisis fundado en una de las manifestaciones del método empírico. En este caso, la información obtenida mediante la experiencia- encuesta se cuantifica y se analiza.

${ }^{9}$ ASHLEY STEDMAN-YUNIS, J.-ALIAKBARI, E. Annual Survey of Mining Companies: 2019, 25 febrero 2020.
} 


\section{Figure 3: Investment Attractiveness Index}

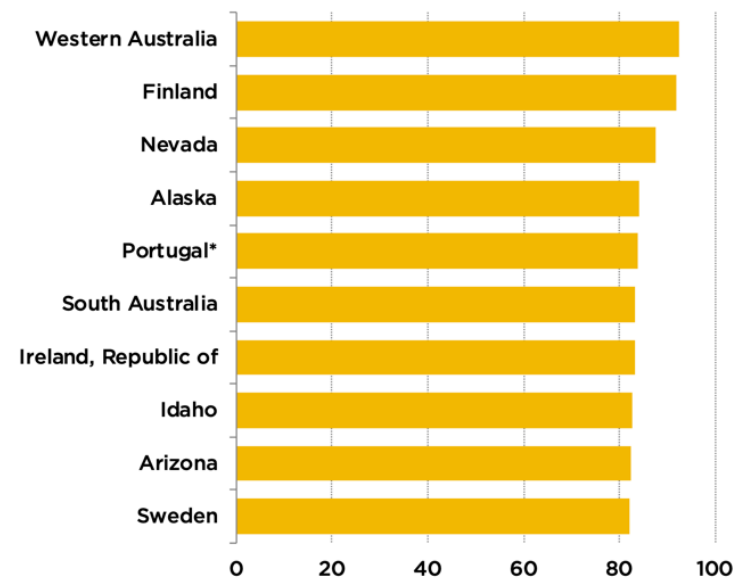

Por su parte, la clasificación de los peor clasificados según el IAI empezando por el peor son:

1․ Tanzanía, que reemplazó a Venezuela como el Estado menos atractiva del

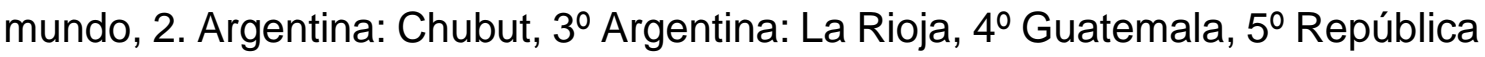

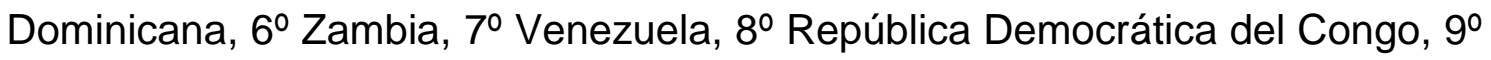
Malí y $10^{\circ}$ Nicaragua.

\section{En especial, el Policy Perception Index o índice de percepción de políticas públicas (IPPP)}

\section{a. Concepto}

El índice de percepción de políticas públicas (en adelante IPPP) es un índice que mide el atractivo regulatorio general de las jurisdicciones. Se compone de respuestas de la encuesta relativas a factores de las políticas públicas que afectan a las decisiones de inversión, tales como el marco regulatorio, incertidumbres, duplicidades, estabilidad política, mano de obra, entre otros. Como pone de manifiesto la propia encuesta Fraser sobre empresas mineras mientras consideraciones geológicas y económicas son factores importantes en la explotación minera, el clima regulatorio de una región tambien es un factor importante en las decisiones de inversión. No obstante, siendo útil medir el nivel de atractivo de los Estados y regiones basado en factores regulatorios, sólo el $40 \%$ los encuestados responden que sus decisiones inversoras están determinadas por factores normativos. Quiere decirse que el $60 \%$ es decir, la 
mayoría, manifiestan que las decisiones de inversión se basan principalmente en el potencial mineral del Estado o región ${ }^{10}$.

Y es aquí que se justifica el estudio del caso de la República de Irlanda, toda vez que ocupa el puesto segundo este año, el puesto cuarto el año pasado y en los cuatro años anteriores y de manera consecutiva el puesto primero de la clasifición.

\section{b. Las preguntas}

Desde 2013 se repiten en las encuetas Fraser a los encuestados en qué medida cada uno los siguientes 15 factores regulatorios influyen en las decisiones de inversión de sus empresas en un Estado, región o provincia. En defintiva, desde hace 5 años se mantienen estas 15 preguntas relativas a los condicionantes regulatorios que estimamos oportuno exponer:

1. Incertidumbre relativa a la Administración, intepretación y aplicación de las regulaciones vigentes;

2. Incertidumbre con respecto a las reglamentaciones ambientales (estabilidad de las reglamentaciones, consistencia y puntualidad del proceso regulatorio, regulaciones no basadas en ciencia);

3. Duplicación e incoherencias regulatorias (incluye federal / provincial, federal / estatal, superposición interdepartamental, etc.);

4. Sistema procesal (justo, transparente, no corruptos, eficiente, plazo etc.);

5. Régimen fiscal (carga fiscal y complejidad del cumplimiento tributario);

6. Incertidumbre sobre reclamaciones relativas a la tituaridad de la tierra;

7. Incertidumbre sobre espacios y otras categorías similares que sean de especial protección tales como espacios áreas naturales, silvestres, parques, sitios arquelógicos etc.

8. Infraestructuras (carreteras, disponibilidad de energía, etc.);

\footnotetext{
10 Vid. Resumen ejecutivo de Ashley STEDMAN-KENETH P. GREEN Annual Survey of Mining Companies: 2017, 22 Febrero 2018, https://www.fraserinstitute.org/studies/annual-survey-ofmining-companies-2017.
} 
9. Acuerdos socioeconómicos / condiciones de desarrollo de la comunidad (se incluyen infraestructuras sociales como escuelas u hospitales);

10. Barreras comerciales (barreras arancelarias y no arancelarias, restricciones a la repatriación de beneficios, restricciones de moneda);

11. Estabilidad política;

12. Regulaciones laborales / acuerdos de empleo y sindicatos / clima laboral;

13. Calidad de la base de datos geológica (incluye calidad y escala de mapas, facilidad de acceso a la información, etc.);

14. Nivel de seguridad (incluye ataques terroristas, grupos criminales o de guerrilla, etc);

15. Disponibilidad de mano de obra y su cualificación.

A los encuestados se les pidió que evaluaran solo aquellos Estados y/o regiones con los que estaban familiarizados. Las opciones de respuesta a cada pregunta son las cinco siguientes:

1 Alienta la inversión.

2 No es un factor disuasorio para la inversión.

3 Es un factor disuasorio leve para la inversión.

4 Es un factor disuasorio fuerte para la inversión.

5 No realizaría inversiones en esta región debido a este factor.

Por último, señalar que la encuesta también incluyó preguntas sobre los propios encuestados y el tipo de compañía que representaban, y otros datos interesantes como "historias de horror" regulatorias, pero también ejemplos de "política ejemplar", o de ejemplos de "mejores prácticas".

\section{c. Los resultados}

Los mejor clasificados desde el punto de vista del IPPP son: 1ํ Finlandia que desplazó a Saskatchewan del primer lugar este año con la puntuación más alta del IPPP (100/100), 2º República de Irlanda que pasó del cuarto lugar en el año

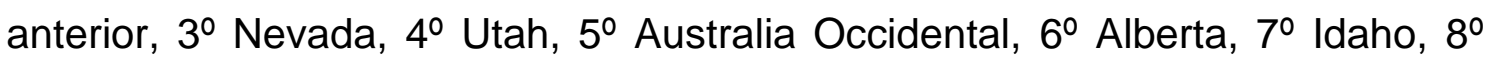
Terranova y Labrador, $9^{\circ}$ Saskatchewan y $10^{\circ}$ Arizona. 


\section{Figure 4: Policy Perception Index}

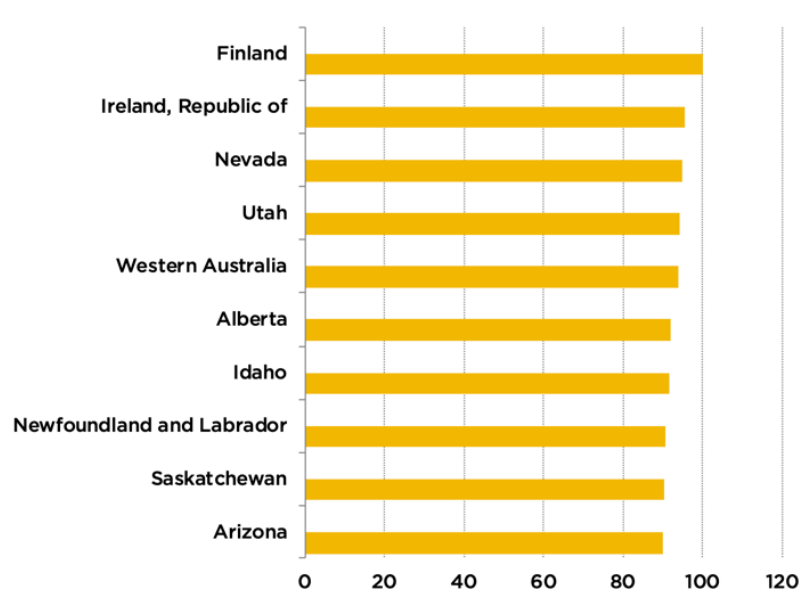

Por contraste, los diez ordenamientos menos atractivos para las inversiones mineras basadas en el IPPP comenzando por el peor clasificado según la encuesta Fraser 2020 son: 1o Venezuela, 2ํ Zimbabwe, 3o Tanzania, 4o

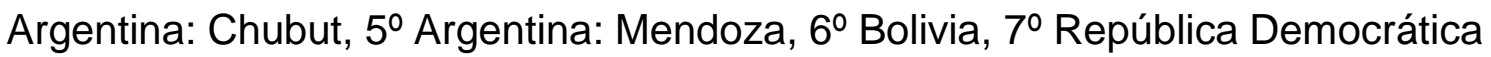

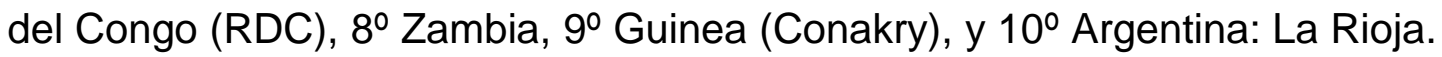

Europa es la región que suele aglutinar mayor número de países entre los diez primeros puestos de la clasificación mundial según el IPPP -aunque no en la actual encuesta de febrero de 2020- siendo por tanto considerados como entornos regulatorios atractivos para la inversión minera. Así la República de Irlanda, Finlancia y Suecia suelen estar bien posicionados en la clasifición anual desde la perspectiva del atractivo de sus políticas públicas mineras ${ }^{11}$.

Por lo que concierne a España, no se la ha podido incluir en la encuesta de 2019 debido al insuficinte número de respuestas recibidas por parte de las empresas a las preguntas formuladas. No obstante, de 2015 a 2017 fue mejorando progresivamente su posición en la clasificación según el IPPP. En 2015 se situaba en el puesto 35 de un total de 109 Estados y regiones, en 2016 se

\footnotetext{
11 Vid. Encuesta Fraser 2017, ob. cit. pág. 44 en la que según manifestaciones de algunos encuestados la República de Irlanda es un Estado "en el que hacen lo que dicen, constantemente, y de una manera transparente. Los funcionarios tienen una actitud de "sí se puede" que sigue las leyes del país, lo que es un cambio refrescante"; "tramita las licencias de manera adecuada (normalmente entre 1-2 meses) y los permisos para perforar pueden ser emitidos en semanas. La eficiente Administración de Irlanda en última instancia, fomentan la inversión".
} 
posicionó en el puesto 24 de 104, en 2017 pasa a ostentar el puesto 18 de un total de 91 Estados evaluados. Por último, en 2018 empeora al ocupar el puesto 3912. No obstante, según la mayoría de los encuentados factores regulatorios tales como la incertidumbre en la interpretación y ejecución de la normativa aplicable, incluyendo la regulación ambiental, duplicidades y el sistema legal en España no son factores que estimulen la inversión, aunque tampoco constituyen elementos que disuadan de la misma ${ }^{13}$. La conclusión es cabal: el margen de mejora es pues claro y posible.

\section{d. La importancia de la tramitación de los procedimientos de otorgamiento de los permisos mineros}

Indudablemente, dentro del índice de atractivo de políticas públicas ocupa un papel destacado el marco regulador de los procedimientos de otorgamiento de los títulos mineros, así como de toda otra autorización o medida de intervención con relación a la planificación territorial, al control ambiental y sectorial de las actividades extractivas. A este respecto, resultan factores cardinales el tiempo de tramitación de los procedimientos, la transparencia, seguridad jurídica y la coordinación interadministrativa. Hay que subrayar que nuestro análisis no aboga por una elemental desregulación del sector en el sentido de descargar de intervenciones y controles para reducir riesgos y sobrecostes para la industria. Por el contrario, se trata de contar con datos que permitan una mejor regulación de la actividad, un marco jurídico de más calidad para el sector y el resto de los intereses y bienes jurídicos implicados -especialmente la protección ambientallo que incluye también -pero no solo- que los procedimientos sean tan eficientes y rentables como sea posible ${ }^{14}$.

\section{d.1. El factor tiempo}

Como dice el refrán "el tiempo es oro" y constituye también un factor decisivo en la calidad regulatoria y su aplicación. El tiempo de tramitación de los procedimientos de otorgamiento de los títulos mineros forma parte de los

\footnotetext{
12 Vid. la evolución de la posición de España según el IPPP en la Encuesta anual de empresas mineras 2017, 22 de febrero 2018, pág. 16.

${ }^{13}$ Vid. Encuesta Fraser 2017, ob. cit. tabla 15 pág.48; tabla 16 pág. 49, tabla 17 pág. 50 y tabla 18 pág. 51.

${ }^{14}$ En sentido similar se manifiestan ASHLEY STEDMAN -KENNETH P. GREEN en Permit Times for Mining Exploration in 2017 Fraser Institut, 2018, pág. 4.
} 
condicionantes que confoman el IPPP. Si la tramitación de los procedimientos se alarga indefinidamente o carece de transparencia o seguridad jurídica, la confiaza decae, se producen sobrecostes y eso puede provocar que los inversores prefieran invertir en otros lugares ${ }^{15}$. Los procedimientos de obtención de los permisos minero ${ }^{16}$ se analizan por el Instituto Fraser de manera específica y monográfica en los estudios Permit Times for Mining Exploration in 2016 Fraser Institut, 2017 y Permit times for mining exploration in 2017, Fraser Institute, 2018 ${ }^{17}$, aunque hay que advertir que dichos estudios se limitan a Canadá, EEUU, Australia y los paises escandinavos de Finlandia y Suecia. Por su parte, en la más reciente Anual Mining survey $2019^{18}$ se incluye un apartado específico dedicado al tiempo de tramitación de los permisos mineros, pero no comprende países europeos.

Constituyen aspectos relevantes el tiempo medio de tramitación de los permisos mineros (duración de los procedimientos), nivel de transparencia y el grado de certidumbre del marco normativo aplicable lo que se traduce en el dato objetivo del porcentaje de resoluciones dictadas dentro del plazo máximo legal establecido. La conclusión es que el tiempo de tramitación de los títulos mineros se ha incrementado en los últimos diez años. El estudio correspondiente al año $2017{ }^{19}$ concluye que según el $53 \%$ de los encuestados el plazo se había alargado en las regiones canadienses respecto de los diez años anteriores. Asímismo, el $71 \%$ responde que en las regiones mineras canadienses obtienen los permisos mineros en un plazo de 6 meses o inferior; frente al 59\% entre las jursdiciones

\footnotetext{
${ }^{15}$ Así lo manifiestan KENNETH P. GREEN-TAYLOR JACKSON en Permit Times for Mining Exploration in 2016 Fraser Institut, February 28, 2017.

16 Téngase en cuenta que tal y como se especifica en el primer estudio Fraser sobre el tiempo de tramitación de los premisos mineros KENNETH P. GREEN-TAYLOR JACKSON Permit Times for Mining Exploration in 2016, ob. cit el término Permit usado en el trabajo es un concepto amplio pues "The name or type of permit needed varies greatly among the provinces and territories. "Permit" will be used in this publication as a general term for the varieties of different requirements in each province and territory" pág. 3, nota 1. Quiere decirse pues que esta cuestión requiere un análisis más detallado por países y en el caso de España por CCAA y exige distinguir entre los títulos mineros regulados en la Ley de Minas de 1973 y la tramitación del resto de autorizaciones necesarias desde la perspectiva de la planifición territorial y urbanística, así como mediombiental para su obtención, estudio que por lo demás consideramos necesario e imprescindible.

${ }_{17}$ Cuyos autores son ASHLEY STEDMAN -KENNETH P. GREEN.

${ }^{18}$ En págs. 41 y sigs de la referida encuesta.

19 Permit times for mining exploration in 2017, Fraser Institute, 2018.
} 
de EEUU, el $43 \%$ en Australia y el $48 \%$ en Suecia y Finlandia. Según la encuesta de 2017 Suecia tramita los títulos mineros en un plazo más corto que Finlandia ${ }^{20}$.

En el caso de los países europeos analizados, el 50\% de los encuentados respondieron que en Finlandia el tiempo de resolución de los procedimientos se había alargado algo o considerablemente respecto de los últimos diez años y en el caso de Suecia el 55\%. Tanto Finlandia como Suecia obtienen buenos resultados en comparación con otros Estados por lo que respecta a la certeza cronológica o grado de cumplimiento del tiempo máximo de resolución de los procedimientos normativamente establecidos: un $45 \%$ de los encuestados para el caso de Suecia y un 50\% para Finlandia, indican que los plazos para las resoluciones de aprobación de permisos se cumplieron entre el $80 \%$ y el $100 \%$ dentro del tiempo máximo legalmente establecido. Gozan pues de altísimo grado de certeza y seguridad jurídica en el cumplimiento de la norma en cuanto a la tramitación de los procedimietos, lo que contrasta con el dato de que tanto en Finlandia como en Suecia comparativamente con el resto de las regiones analizadas se require un tiempo relativamente largo para otorgar los permisos necesarios.

En esta dirección estimamos muy necesario y oportuno llevar a cabo un estudio comparado de los diferentes ordenamientos de los países europeos que distinga entre los diferentes títulos habilitantes que inciden en la actividad extractiva, poniendo al final el foco en el que habilita para la explotación, con el objeto de poner de relieve similitudes y diferencias, así como fortalezas y debilidades. Se trata de un análisis muy útil y necesario llevar a cabo también en España y por CCAA, diferenciando entre las CCAA que se han dotado de normativa minera propia; y el resto, como la Comunidad Autónoma andaluza que -aunque sin Ley minera propia- sí proclama como una prioridad de sus políticas la actividad

\footnotetext{
20 Según la Encuesta Fraser de 2017 para el caso de Suecia el 18\% de los encuestados indicaron que se les otorgaron los pemisos mineros en un plazo de dos meses o inferior y el $45 \%$ respondió que se les otorgaron tales títulos en un plazo de 6 meses o inferior; frente a Finlandia donde el $11 \%$ de los encuestados indicaron que se les otorgaron los pemisos mineros en un plazo de dos meses o inferior y el 22\% respondió que se les otorgaron tales títulos en un plazo de 6 meses o inferior. En Finlandia según el $44 \%$ de los encuestados el plazo de otorgamiento de los títulos mineros fue de 15 meses o más.
} 
extractiva sostenible y cuenta con una Estrategia minera ahora pendiente de renovación ${ }^{21}$.

\section{d.2. Otros indicadores: transparencia, seguridad jurídica y confianza legítima}

Otros factores relevantes que inciden en la tramitación de los procedimientos de otorgamiento de permisos mineros son la transparencia, la seguridad jurídica y la confianza legítima.

Integran la transparencia en este asunto tanto el grado de comprensión del marco normativo aplicable como su interpretación y aplicación tanto por la autoridad competente (Administración) como por los tribunales. Si hay interferencias políticas o incluso riesgo de corrupción, contaminarán la tramitación.

Es importante tambien la confiaza del sector minero encuestado en que se le otorgará el permiso, una vez cumplidos todos los requisitos legales establecidos. Si las empresas no están seguras de que obtendrán los permisos necesarios para realizar las actividades mineras una vez que se hayan reunido los requisitos legalmente establecidos, es menos probable que decidan invertir en dicho Estado o región. Lógicamente esta cuestión está derechamente relacionada con el grado de discrecionalidad de la Admnistración en el otorgamiento de los títulos mineros, asi como de otras técnicas de intervención que inciden en la actividad minera ${ }^{22}$. En este sentido, el estudio Fraser 2017 destaca que para Finlandia el $100 \%$ y en el caso de Suecia el $91 \%$ de los encuestados tienen un alto grado de confianza en que se les otorgarán los permisos solicitados.

Constituyen pues aspectos relevantes a considerar a efectos de encarar la mejora regulatoria el acceso y comprensión de la normativa minera, grado de certeza y seguridad jurídica, así como el factor tiempo en la tramitación y resolución de los procedimientos de otogamiento de los títulos habilitantes mineros, distinguiendo entre el marco teórico es decir, el plazo máximo legalmente establecido para la resolución de tales procedimientos y el tiempo

${ }^{21}$ Acuerdo de 28 de junio de 2016, del Consejo de Gobierno, por el que se aprueba la Estrategia Minera de Andalucía 2020.

${ }^{22}$ Como evaluación de impacto ambiental, licenias urbanísticas, autorizaciones en materia de aguas, etc. 
medio efectivo en que la Administración competente resuelve los mismos. A mayor diferencia entre el plazo legal y el efectivo, mayor incertidumbre generará el sistema para todos los interesados, empresas y ciudadanos.

De las encuestas anuales del Instituto Fraser se concluye que la variable regulatoria que recibe la valoración más negativa en relación con el tiempo para la obtención de un permiso minero es la incertidumbre con relación a la interpretación y aplicación del ordenamiento jurídico por la Administración.

\section{RÉGIMEN JURÍDICO DE LA MINERÍA EN LA REPÚBLICA DE IRLANDA: LA MINERALS DEVELOPMENT ACT 2017}

Como se ha visto, los resultados de las encuestas Fraser justifican sobradamente el análisis del marco normativo de la República de Irlanda, pues este año ocupa el puesto número dos, pero ha ocupado el puesto número uno varios años de manera consecutiva según el IPPP. Nuestro estudio se va a centrar en los procedimientos de otorgamiento de los permisos mineros.

La República de Irlanda tiene un potencial minero muy imporante, a pesar de su tamaño relativamente pequeño $(70,000 \mathrm{~km}$ cuadrados), país en el que la minería está presente desde hace unos 4000 años. Las rocas carbonatadas del periodo carbonífero inferior de las Midlands irlandesas albergan uno de los grandes yacimientos de mineral del mundo. Desde 1960, se han descubierto 14 depósitos significativos de zinc y plomo. Irlanda ocupa el primer lugar a nivel mundial en términos de zinc descubierto por $\mathrm{km} 2$ y el segundo con respecto al plomo. Asimismo, tiene un gran potencial de minerales industriales. Además hay minas de plata, cobre, azufre y oro.

El ordenamiento jurídico de la República de Irlanda se enmarca en un compromiso proactivo del Gobierno para priorizar la exploración y el desarrollo responsable de sus recursos minerales, lo que incluye máxima transparencia, publicidad de datos y actualización. La política en Irlanda tiene por objeto promover la exploración minera para permitir el descubrimiento y explotación de yacimientos económicamente rentables. El objetivo es maximizar la contribución del sector minero a la economía, con el debido respeto a su impacto social y 
ambiental. Las actividades son llevadas a cabo por el sector privado con permisos emitidos por el Ministro.

La República de Iranda ha hecho un esfuerzo por dotarse de una "legislacion fácil de usar" "User-friendly legislation". Hay seguridad y directrices ambientales sencillas, así como un favorable régimen fiscal.

Por lo demás y como ya manifestó LEGOUX23 "las actividades mineras son, al menos en la mayor parte de estos países, muy antiguas; las reglas de derecho que les han sido aplicadas han evolucionado en el curso del tiempo, aunque frecuentemente, demasiado frecuentemente, los textos actualmente en vigor quedan marcados de recuerdos —un geólogo diría «reliquias estructurales»-, respetables en verdad, pero poco adaptados a las condiciones modernas de investigación y explotación minera". Sin embargo, si hay algo que de entrada destaca del marco normativo de la minería en Iranda es su actualización y permanente revisión como objetivos del Ministro del ramo, por contraste, por ejemplo, con el caso de España cuya LMi es de 1973.

El marco jurídico de la minería en Irlanda estaba integrado por las Leyes 1940 a 1999 y los reglamentos dictados en su desarrollo. Más recientemente, se ha aprobado la Minerals Development Act de 2017 (número 23 of 2017) en la que centraremos nuestro análisis. Los aspectos medioambientales se regulan por legislación nacional y Directivas de la UE.

La Minerals Development Act 2017 (en adelante MDA) tiene por objeto consolidar, modernizar y simplificar la legislación minera -prospección y explotación y actualizar ciertos aspectos de acuerdo con las mejores prácticas actuales, reemplazando el compendio de legislación de 1940 a 1999. Asimismo, el art. 216 concede al Ministro potestad reglamentaria para el desarrollo de la Ley ${ }^{24}$.

\section{Definición de minerales y ámbito de aplicación de la legislación minera ${ }^{25}$}

\footnotetext{
23 LEGOUX, P. "Legislaciones mineras de los Estados miembros de la Comunidad Económica Europea", RAP, no 113, 1987, págs. 365-366.

${ }^{24} \mathrm{El}$ precepto establece que estos reglamentos tras su adopción se presenten ante cada Cámara del Parlamento (Oireachtas).

${ }^{25}$ La exploración de uranio está prohibida en Irlanda desde 2007, asimismo los arts. 224 a 228 de la MDA de 2017 incorporan el art. 3.3 de la Convención de Minamata sobre el mercurio aprobada en Ginebra el 19 de enero 2013.
} 
Según el art. 2 MDA se entiende por minerales:

"todas las sustancias, incluidos los minerales que se producen naturalmente en, sobre o debajo del suelo, o que se producen en los residuos extractivos, e incluyen, si las sustancias se extraen, el espacio cúbico anteriormente ocupado por esas sustancias (yacimientos), pero no incluye: a) suelo superior, b) césped o turba, c) agua, d) petróleo, e) piedra, grava, arena o arcilla, que no sean un scheduled mineral (mineral programado).

La ley incluye en su ámbito de aplicación entre sus definiciones el concepto de "scheduled mineral" que se refiere a una lista de materias primas que se incluyen en la definición de minerales princialmente metálicos y minerales industriles tales como oro, plata cobre, plomo, estaño, barita, mercurio tiza, arcilla, feldespato y yeso que son de titularidad estatal ${ }^{26}$. En cambio, los minerales "Non-scheduled" como la piedra, la arcilla, la grava y la arena pertenecen al propietario de la tierra. En conclusión, esto significa en la práctica que la mayoría de las canteras que producen agregados para la industria de la construcción, cal o piedra etc. para edificios o lápidas, no son minerales incluidos en esta Ley y no están sujetos a los permisos mineros de la legislación minera.

Los hidrocarburos, es decir, petróleo y gas natural se regulan desde la Petroleum Minerals Development Act 1960 por su legislación específica, quedando excluidos del ámbito de aplicación de la legislación minera.

Por su parte, el art. 6 en relación al ámbito de aplicación de la norma ordena su aplicación a los minerales y sustancias definidas en el art. 2 que se hallen en los fondos marinos y el subsuelo de:

(a) los mares territoriales en el sentido de Sea-Fisheries and Maritime Jurisdiction Act $2006^{27}$ o (b) cualquier área delimitada en cada momento en virtud del art. 2 de la Continental Shelf Act, 1968.

26 Véase en la MDA 2017 Schedule List of Minerals.

27 Ley de Pesca y Jurisdicción Marítima de 2006. 
Así pues, se contiene una expresa referencia a la aplicación de la norma y sus procedimientos a la minería de los fondos marinos del mar territorial y plataforma continental de la jurisdicción de la República de Irlanda.

\section{Titularidad o propiedad de los recursos minerales}

Es un sistema mixto y complejo. Los recursos minerales en Irlanda pueden ser del Estado o de titularidad privada. El 60\% de los recursos minerales son de propiedad del Estado (todas las minas de oro y plata) y el $40 \%$ restantes de titularidad privada. La propiedad privada de minerales tiene su origen fundamentalmente en las tierras que no han sido tranferidas o adquiridas por la Comisión de Tierras de Irlanda desde 1903.

Mas, con independencia de la titularidad privada o estatal de los recursos minerales, el derecho de explotación se atribuyó en exclusiva al Estado a través del Ministro en virtud de la Minerals Development Act de 1979. Las excepciones fueron los minerales que se encontraban en explotación por propietarios privados en el momento de la entrada en vigor de la citada Ley de 1979. Para esos casos, se estableció el pago de la correspondiente indemnización al titular privado de dichos recursos minerales.

\section{Los permisos mineros}

Nuestro estudio se centra en la valoración del régimen jurídico de los títulos mineros en la Mineral Developing Act 2017. Con carácter preliminar, es preciso hacer una importante aclaración terminológica. En la normativa minera irlandesa la "prospección" es el proceso de exploración e investigación con el objeto de encontrar yacimientos de minerales económicamente viables (art. 2 MDA). Comprende pues lo que en la LMi 1973 constituye la exploración y la investigación. Por su parte, "mining" o working hace referencia a la extracción o explotación de minerales (art. 5).

En la actualidad la compentencia en materia de minas corresponde al Ministro de Comunicaciones, Acción Climática y Medio Ambiente, en particular, the Exploration and Mining Division (EMD) -la División de Exploración y Minería del Ministerio-, es la autoridad reguladora competente para la exploración y explotación de los minerales. 
De manera esquemática los títulos mineros en la MDA son los siguientes:

- La exploración está sujeta a la Prospecting licence $(\mathrm{PL})^{28}$ y/o la Retention licence $(\mathrm{RL})$. Las licencias de prospección y licencias de retención otorgan el derecho exclusivo de exploración para los minerales especificados en la licencia en un área geográfica definida conocida como área de licencia de prospección. Las áreas son de aproximadamente $35 \mathrm{~km} 2$ con sus perímetros generalmente siguiendo los límites de la ciudad.

Una licencia de prospección normalmente tendrá una validez de seis años y habilita a su titular a realizar diversas actividades en la búsqueda de minerales especificados. Las licencias de prospección pueden renovarse.

-La extracción está sujeta a la Mining licence (ML) o la licencia minera.

Como ya se ha indicado, los minerales en Irlanda pueden ser pertenencias del Estado o de privados. Con independiencia de la titularidad se requiere para su explotación una State Mining Facility otorgada por el Ministro. La licencia de extracción se denominaba hasta 2017 State Mining Lease (arrendamiento minero estatal) en la Ley de 1940 para los minerales de titularidad del Estado. En cambio, se requería una State Mining Licence si la extracción recaía sobre minerales privados de conformidad con la Minerals Development Act 1979. La Ley de 2017 ha simplificado la regulación, pues a partir de su entrada en vigor la Mining licence (en adelante ML) licencia minera es una licencia de explotación única, con independencia de que los minerales sean de titularidad estatal o privada, acabando con la diferenciación terminológica y de procedimiento.

El procedimiento de otorgamiento de la ML se regula en los arts. 54 a 84 . El Ministro es el órgano competente para otorgar una licencia minera en un sistema de ventanilla única. Una licencia de explotación puede derivar de una previa PL o $R L$.

Para la extracción de minerales hay tres licencias separadas que se deben obtener:

${ }^{28}$ Se regulan en los arts. $16-47$ de la MDA. 
Una licencia de control integrado de contaminación (integrated pollution control IPC) de la Agencia de Protección Ambiental (Environmental Protection Agency (EPA). Las licencias de IPC tienen como objetivo prevenir o reducir las emisiones a la atmósfera, el agua y la tierra, reducir los desechos y utilizar la energía / recursos de manera eficiente. Una IPC es una licencia integrada única que cubre todas las emisiones de la instalación y su gestión ambiental.

Permiso de planificación de la autoridad local (incluida una evaluación completa del impacto ambiental y consulta pública).

El Ministro no puede otorgar la licencia minera hasta que se hayan obtenido previamente tanto el permiso de planificación como la licencia de IPC.

\section{Fortalezas y debilidades del régimen jurídico de los permisos mineros en Irlanda}

Irlanda tiene una política nacional clara y coherente con relación a sus minerales que proclama como objetivo el fomento de la minería con elevados estándares de sostenibilidad ambiental y social, en consonancia con las directrices de la UE desde la Comunicación de la Comisión Abordar los retos de los mercados de productos básicos y de las materias primas, 2.2.201129. Sin embargo, la República de Irlanda, por contraste con otros países europeos como los nórdicos (Finlandia ${ }^{30}$, Noruega ${ }^{31}$, Suecia ${ }^{32}$ ) y más recientemente el Reino Unido ${ }^{33}$ no ha aprobado formalmente una estrategia nacional sobre minerales ${ }^{34}$, lo que no ha impedido desarrollar una efectiva estrategia minera que situa al país entre los primeros puestos de la clasificación mundial que elabora el Instituto Fraser con relación al IPPP.

La política de fomento de la minería se traduce en un marco regulador de la actividad minera integrado por la legislación minera en sentido estricto, así como

\footnotetext{
${ }^{29}$ Comunicación de la Comisión al Parlamento europeo, al Consejo, al Comité Económico y Social y al Comité de las Regiones Abordar los retos de los mercados de productos básicos y de las materias primas, 2.2.2011COM (2011) ob. cit.

30 Finland's mineral strategy: visión 2015, 2010.

31 Strategy for the Mineral Industry, Ministry of Trade and Industry, marzo 2013.

${ }^{32}$ Sweden's Minerals Strategy for sustainable use of Sweden's mineral resources that creates growth throughout the country, june 2013.

${ }_{33}$ Vid UK Minerals Strategy. Meeting the demand for minerals and mineral products sustainably for the next 25 years, juy 2018.

${ }^{34}$ Vid en este sentido MONTOYA MARTÍN, E. "Introducción" en Minería extractiva, planificación territorial y urbanismo, MONTOYA MARTÍN, E. (Dir.) Tirant lo Blanch Valencia 2020, pág. 15 y sigs.
} 
la normativa de protección ambiental y planificación territorial, con elevadas dosis de coherencia y coordinación entre las Administraciones implicadas, de tal manera que no hay solapamiento competencial.

La República de Irlanda ha hecho un esfuerzo por dotarse de una legislación minera "User-friendly legislation", fácilmente comprensible, dotada de seguridad jurídica y directrices ambientales sencillas, así como un favorable régimen e incentivos fiscales. Además, la legislación minera ha sido objeto de actualizaciones periódicas que han culminada en la vigente Ley de 2017 que incorpora la referencia a la minería oceánica, a las nuevas tecnologías, los estándares y buenas prácticas ambientales y el objetivo de la simplificación y mejora continua de la legislación. En este sentido, la vigente Mineral Development Act ha simplificado los títulos mineros dado que la extracción se sujeta al otorgamiento de un único título habilitante, la ML, necesaria tanto para los recursos minerales de titularidad estatal como para los de propiedad privada, acabando con la dicotomía precedente que sujetaba a títulos de intervención administrativa distintos cada uno con sus respectivos procedimientos: State Mining Lease para los minerales de titularidad del Estado y State Mining Licence para la extracción de minerales de titularidad privada.

El régimen de propiedad de los minerales en la República de Irlanda es mixto y complejo. El $60 \%$ de los recursos minerales son de propiedad del Estado, y el $40 \%$ restante de titularidad privada, que hunde sus raíces históricas en las transferencias y adquisiciones de tierras llevadas a cabo por la Comisión de Tierras de Irlanda, no resultando siempre fácil averiguar quién es titular de los derechos mineros en una finca, pues pueden ser de su propietario o de un tercero. Sin embargo, el régimen de propiedad de los recursos minerales ${ }^{35}$, que no de su exploración y explotación que es de titularidad exclusiva del Estado, resulta ser un factor "neutro" que no incide en la calidad del marco regulatorio de la actividad extractiva, en indicadores tales como comprensión, coherencia, seguridad jurídica, coordinación y tiempos de respuesta de los procedimientos.

\footnotetext{
35 Véase el ya clásico trabajo de VERGARA BLANCO, A. Principios y Sistema del Derecho minero. Estudio histórico dogmático, Edit. jurídica de Chile, 1992, pág. 33 en el que señala que lo importante en las minas no es la titulirdad sino la función.
} 
El apoyo a la actividad minera se traduce en una regulación que fomenta y favorece la exploración ${ }^{36}$, actividad previa y trascendental para, en su caso, hallar y posteriormente extraer minerales económicamente rentables a través de la Prospecting Licence (PL), cuyo otorgamiento es competencia del Ministro de Comunications, Climate Action and Environment y no está sujeta a instrumentos de control ambiental, aunque sí a la guía de buenas prácticas ambientales. Para la prospección en tierra y en el mar, el Ministerio y el EMD actúan como "ventanilla única" para el otorgamiento, control y regulación de las licencias de prospección. Aunque se puede requerir permiso para ciertas actividades de otros órganos y autoridades (por ejemplo, el Ministro de Arte, Patrimonio y la Gaeltacht para acceder a las Reservas Naturales Nacionales), dichos permisos, excepto de la Autoridad de Aviación de Irlanda, se canalizan a través de EMD, lo que contribuye a una gestión administrativa eficiente de los permisos de prospección.

Con carácter previo a la solicitud de una PL puede tener lugar a instancia de un interesado una Statement of interest, es decir una anotación preventiva de interés en la futura actividad de exploración para la zona y minerales solicitades. Se trata pues de una suerte de reserva de interés en emprender futuras actividades de prospección, que se mantiene durante el plazo determinado ad casum que decide el Ministro en la declaración hasta que se recibe una solicitud de $\mathrm{PL}$, en cuyo caso si el titular de la declaración presenta en tiempo y forma solicitud de $\mathrm{PL}$, procederá su otorgamiento por un procedimiento de concurrencia competitiva.

Por su parte, la Retention licence $(R L)$ licencia de retención es una novedad de la actual MDA de 2017 y como su nombre indica supone la retención del derecho de exploración a favor del titular de una licencia de prospección cuando lo solicite antes del término del plazo para el que se hubiera otorgado siempre que en esa fecha haya descubierto minerales y concurra la circunstancia de que no es todavía económicamente viable explotar los minerales, aunque es razonable esperar que lo sea en el futuro; o que existen dificultades ambientales, de acceso $u$ otras que impiden que los minerales se extraigan por el momento,

${ }^{36}$ Por cierto, en sentido opuesto el Borrador de Proyecto de Ley de minas de España de noviembre de 2014 que suprimía incomprensiblemente la licencia de exploración. 
siempre que en ambos casos el Ministro estime que la exploración de los minerales es de interés público.

La extracción de minerales está sujeta a la mining licence (ML). En el procedimiento de otorgamiento debemos distinguir dos supuestos: denegación de la ML antes del trámite de información pública cuando la solicitud no cumpla con los requisitos legales, y resolución del procedimiento tras el preceptivo trámite de información pública, que es el supuesto normal. En este segundo caso, cuando se hayan presentado alegaciones en el trámite de información pública se abre la posibilidad de que el Ministro decida la intervención del Mining Board (Junta Minera) autoridad cuasi jurisdiccional e independiente ante la que puede celebrarse un trámite de vista al objeto de pronunciarse por vía de recomendaciones sobre las alegaciones presentadas. El Ministro puede igualmente decidir la no celebración de dicho trámite. El plazo de resolución del procedimiento es breve fijando el plazo máximo en 90 días contados a partir de la celebración del trámite de información pública. Por lo demás, y por contraste con la legislación minera del resto de los países europeos, la normativa irlandesa no establece el plazo de duración de la ML, sino que la duración se establece en función de la duración de las operaciones de extracción previstas. Es una muestra más de su flexibilidad.

Con carácter previo a la Mining licence, son necesarios dos permisos para proceder a la extracción de minerales: de una parte, el permiso de planificación Planning Permission regulado por la Planning and Developement Acts, y la Integrated Pollution Prevention and Control Licence (autorización integrada de la contaminación) regulada por Enviromental Protection Agency Act 1992. Destaca una estrecha comunicación y coordinación entre la autoridad local, la Agencia de Protección ambiental y el propio Ministerio competente en minería que son las tres autoridades administrativas responsables de la emisión de estas licencias, cooperación importante en aras de garantizar que el procedimiento de otorgamiento de permisos sea lo más eficiente posible, con seguridad jurídica para la industria, al tiempo que permita plantear las preocupaciones de las comunidades locales y garantizar que se mantengan altos estándares ambientales. 
Respecto del factor tiempo, indicador importante en la eficiencia del procedimiento administrativo, es decir, los plazos de tramitación de los títulos mineros, hay que resaltar que la vigente Ley de 2017 no establece un plazo de resolución de los permisos mineros que regula, sino que se limita a disponer un plazo máximo de resolución a partir del trámite de información pública, plazo por lo demás breve expresado en días (90 días). Cabalmente, no regula la Ley un plazo máximo de resolución de las $\mathrm{PL}, \mathrm{RL}$ ni $\mathrm{ML}$.

El tiempo promedio para la emisión de un PL es de cuatro meses (siempre que no se presenten apelaciones). Sin embargo, puede llevar más tiempo y depende casi por completo del tiempo que le toma al solicitante responder a las peticiones de información adicional requeridas por el Ministerio. Los permisos de planificación se otorgan en promedio en diez meses. Una ML normalmente se otorga entre seis y diez meses y una licencia de control integrado de la contaminación siete meses. Lógicametne si tienen lugar apelaciones, el tiempo se alarga. Para grandes yacimientos, el tiempo transcurrido desde la solicitud hasta la emisión de los tres permisos oscila entre dos y cuatro años.

Por lo demás, las tasas de éxito de los permisos para el período 2013-2015 también son muy altas (98\% y $100 \%$ para los permisos de exploración y extracción, respectivamente). No se conocen casos judiciales importantes en Irlanda, lo que indica que la vía judicial no se utiliza con frecuencia para resolver disputas ${ }^{37}$.

Se trata de una Administración con un elevado grado de transparencia e información en materia minera. La transparencia eleva la confianza tanto del propio sector, como de los ciudadanos. En este setido, destacan los Informes semestrales sobre el sector que presenta el Ministro de Comunicaciones, Acción Climática y Medio Ambiente en los que se publican los títulos mineros tramitados, fecha inicio y de finalización, empresas minerales, tasas y cánones recaudados por licencias, estimulos fiscales otorgados, etc.

Por último, se trata de una Administración colaboradora en coherencia con su política minera que se traduce en la elaboración de guías y protocolos que

37 Según Study - Legal framework for mineral extraction and permitting procedures for exploration and exploitation in the EU, Brussels 2017, Anexo, pág. 233. 
facilitan la información y conocimiento de los trámites o fases del procedimiento de otorgamiento de títulos mineros, incluyendo guías ambientales en la materia, al tiempo que mantiene elevados estándares de sostenibilidad ambiental.

\section{EL MARGEN DE MEJORA REGULATORIA EN LA GESTIÓN DE PERMISOS MINEROS EN ESPAÑA: UN ESTUDIO DEL FACTOR TIEMPO}

La encuesta Fraser con la que comenzaba este análisis, pone de relieve la necesidad de un estudio del marco regulatorio de los permisos mineros a nivel europeo -iniciado ya con el Informe Study - Legal framework for mineral extraction and permitting procedures for exploration and exploitation in the EU, Brussels $2017^{38}$, pero también en España, examinando el régimen jurídico de la minería en las CCAA, con especial atención de aquéllas que tienen importantes recursos minerales regulados en la $\mathrm{LMi}$. Es necesario un diagnóstico del régimen jurídico y de su aplicación, de la práctica administrativa y judicial para proponer fundadamente una racionalización del marco regulador. En esa tarea hay varios indicadores a tener en cuenta, uno de ellos, en el que voy a centrarme, es el tiempo.

Para incrementar la seguridad jurídica del sistema y la eficiencia de la gestión administrativa en el sector minero es esencial el factor tiempo, lo que requiere un previo diagnóstico de una parte, del plazo legalmente establecido para la resolución y notificación de los procedimientos y, de otra parte, el tiempo real de la resolución de los mismos. Resulta pues esencial poner de relieve la diferencia entre el tiempo legal y el tiempo real, y analizar las causas de retraso (informes, recursos, descoordinación, falta de medios etc). Si hay grandes diferencias entre el tiempo legal y el real, sólo una vez analizadas sus causas, es posible aportar soluciones para su mejora, que nos permita "repensar el modelo". Porque es fácil sobre el "papel" reducir el plazo legal de resolución y notificación de los procedimientos mineros para luego seguir incumpliendo el deber de resolver y notificar dentro del plazo legalmente establecido. Por otra parte, la mejora regulatoria desde la perspectiva del tiempo no consiste sin más en reducir el plazo legalmente establecido, sino regular un plazo que la Administrción pueda

\footnotetext{
38 Iniciativa muy valiosa como punto de partida, pero análisis que requiere mayor profundización.
} 
cumplir. En definitiva, como hemos señalado, acecar el plazo legal al real, aunque tenga que incrementarse el primero para dar una respuesta con todas las garantías jurídicas necesarias. Lo verdaderamente relevante es a partir del diagnóstico, hallados los problemas, los nudos y factores de obstaculización del procedimiento, es decir las ineficiencias, aportar los medios y regular en la dirección de acercar el plazo legal al real, aunque haya que aumentar el primero, pues eso es un elemento de seguridad jurídica para todos los operadores interesados y, por ende, para el sistema, pues contribuirá a incrementar la confianza en la Administración y atraerá la inversión.

Voy a poner como ejemplo el plazo de tramitación de los títulos mineros en las diferentes CCAA relativos a los recursos de las Sección C y D LMi, toda vez que de acuerdo con los Estatutos de Autonomía todas CCAA son titulares de las competencias para el desarrollo legislativo y la ejecución del régimen minero: permiso de exploración, permiso de investigación, concesión de explotación ${ }^{39}$ y otras cuestiones relacionadas con los mismos como la transmisión de derechos mineros, la caducidad y otros a través del siguiente cuadro-resumen de elaboración propia.

\section{CUADRO: PLAZO LEGAL DE RESOLUCIÓN DE LOS PROCECIMIENTOS RELATIVOS A LOS RECURSOS DE LAS SECCIONES C Y D DE LA LEY DE MINAS EN LAS CCAA}

\begin{tabular}{|c|c|c|c|c|c|}
\hline COMUNIDAD & PERMISO & PERMISO DE & CONCESI & TRANSMISIÓN & DECLARACIÓN \\
\hline \multirow[t]{5}{*}{ AUTÓNOMA } & EXPLORACIÓN & INVESTIGACIÓN & ÓN & DERECHOS & CADUCIDAD \\
\hline & & & & MINEROS & DERECHOS \\
\hline & & & & & MINEROS POR \\
\hline & & & & & RENUNCIA \\
\hline & & & & & VOLUNTARIA \\
\hline ANDALUCÍA & $\begin{array}{c}12 \text { MESES } \\
\text { PRÓRROGA }\end{array}$ & $\begin{array}{c}12 \text { MESES } \\
\text { PRÓRROGA }\end{array}$ & $\begin{array}{l}\text { Concesión } \\
\text { directa }\end{array}$ & $\mathrm{X}$ & $\mathrm{X}$ \\
\hline
\end{tabular}

${ }^{39}$ Con relación a la concesión de recursos de las Secciones C y D Vid. QUINTANA LÓPEZ, T. Concesión de minas y protección del medio ambiente, Tirant lo Blanch, Valencia 2013, págs. 41 y sig. 


\begin{tabular}{|c|c|c|c|c|c|}
\hline & 6 MESES & 9 MESES & 18 MESES & & \\
\hline ARAGÓN & 8 MESES & 8 MESES & 8 MESES & 3MESES & $\begin{array}{c}\text { Caducidad de } \\
\text { derechos mineros } 3 \\
\text { meses OTROS Vid* }\end{array}$ \\
\hline ASTURIAS & 6 MESES & 6 MESES & 60 DÍAS & $\mathrm{x}$ & 6 MESES + \\
\hline BALEARES & $\begin{array}{c}18 \text { MESES } \\
\text { Prórrogas } 6 \\
\text { meses }\end{array}$ & $\begin{array}{c}18 \text { MESES } \\
\text { Prórrogas } 6 \text { meses }\end{array}$ & $\begin{array}{l}18 \text { MESES } \\
\text { Prórrogas } \\
12 \text { meses }\end{array}$ & $x$ & $\begin{array}{c}\text { Procedimiento } \\
\text { sancionador } 12 \\
\text { meses caducidad }\end{array}$ \\
\hline CANTABRIA & $x$ & 8 MESES & $x$ & $x$ & $\begin{array}{c}\text { PROCEDIMIENTO } \\
\text { SANCIONADOR } \\
\mathbf{1} \text { AÑO }\end{array}$ \\
\hline CANARIAS & 3 MESES & $\begin{array}{l}\text { Terrenos francos y } \\
\text { registrables } 9 \\
\text { MESES no Francos } \\
\text { ni registrables } 5 \\
\text { MESES }\end{array}$ & $\begin{array}{c}\text { Derivada } \\
\text { de p. de } \\
\text { investigació } \\
\text { n } 5 \text { MESES } \\
\text { CONCESI } \\
\text { ÓN } \\
\text { DIRECTA } \\
10 \text { MESES }\end{array}$ & $\begin{array}{c}\text { CADUCIDAD } \\
\text { DE P } \\
\text { EXPLORACIÓN } \\
\text { INVESTIGACION Y } \\
\text { CONCESIÓN } 3 \\
\text { MESES SILENCIO } \\
\text { POSITIVO }\end{array}$ & $\begin{array}{c}\text { Declaración de } \\
\text { compatibilidad de } \\
\text { trabajos mineros } 5 \\
\text { MESES SILENCIO } \\
\text { NEGATIVO } \\
\text { DECLARACIÓN DE } \\
\text { INCOMPATIBILIDAD } \\
\text { DE TRABAJOS } \\
\text { MINEROS } 3 \text { MESES } \\
\text { SILENCIO POSITIVO }\end{array}$ \\
\hline $\begin{array}{l}\text { CASTILLA-LA } \\
\text { MANCHA }\end{array}$ & 6 MESES & 6 MESES & 6 MESES & $\mathbf{x}$ & $\mathbf{x}$ \\
\hline $\begin{array}{l}\text { CASTILLA } \\
\text { LEÓN }\end{array}$ & $\begin{array}{c}6 \text { MESES }{ }^{*} \\
\text { PRÓRROGA } 3 \\
\text { MESES }\end{array}$ & $\begin{array}{c}6 \text { MESES }^{*} \\
\text { PRÓRROGA } 3 \\
\text { MESES }\end{array}$ & $\begin{array}{l}6 \text { MESES* } \\
\text { PRÓRROG } \\
\text { A } 3 \text { MESES }\end{array}$ & 3MESES $^{*}$ & $x$ \\
\hline CATALUÑA & $x$ & $\mathrm{x}$ & $\mathrm{x}$ & $\mathrm{x}$ & $\mathrm{x}$ \\
\hline $\begin{array}{c}\text { EXTREMADU } \\
\text { RA }\end{array}$ & $x$ & $X$ & $\mathrm{X}$ & $x$ & $x$ \\
\hline GALICIA & 12 MESES & 12 MESES & 12 MESES & $\begin{array}{c}\text { Concursos de } \\
\text { derechos mineros }\end{array}$ & $\begin{array}{l}\text { Exp sancionador o de } \\
\text { caducidad en minas }\end{array}$ \\
\hline
\end{tabular}




\begin{tabular}{|c|c|c|c|c|c|}
\hline & & & & 6 meses & 12 meses \\
\hline LA RIOJA & $\mathbf{X}$ & $\mathbf{X}$ & $\mathbf{X}$ & $X$ & $X$ \\
\hline MADRID & $\mathrm{X}$ & $X$ & $X$ & $x$ & $\mathrm{X}$ \\
\hline MURCIA & 6 MESES* & 8 MESES* & 8 MESES* & $\mathbf{X}$ & $\mathbf{X}$ \\
\hline NAVARRA & $\mathrm{x}$ & $x$ & $x$ & $x$ & $x$ \\
\hline PAÍS VASCO & 6 MESES* & 6 MESES* & 6 MESES* & $\mathbf{X}$ & $\mathbf{X}$ \\
\hline VALENCIA & 9 MESES & 9 MESES & 9 MESES & $\mathbf{x}$ & $\mathbf{X}$ \\
\hline
\end{tabular}

El cuadro se ha elaborado a partir del análisis del marco jurídico por el que se regula el plazo de resolución de los procedimientos de otorgamiento de los títulos mineros de las Secciones $C$ y $D$ de la LMi en cada CCAA.

Varias son las conclusiones que se extraen de dicho análisis:

En primer lugar, la heterogeniedad de los plazos establecidos para tramitar un mismo título minero en las diferentes CCAA. Dichos plazos sólo en dos casos se disponen en Leyes de ordenación de la minería (Baleares y Galicia), puesto que son las dos únicas CCAA que han promulgado una Ley de minas, mientras que en el resto de las CCAA se establecen en la norma reguladora de los procedimientos de competencia autonómica.

La Comunidad Autónoma con los plazos legales más largos de resolución y notificación de los procedimientos de otorgamiento de los títulos mineros es Baleares, cuya Ley 10/2014, de 1 de octubre, de Ordenación minera dispone el plazo común de 18 meses para los tres títulos mineros exploración, investigación y concesión de explotación, seguida de Andalucía que establece plazos de 12 para el permiso de exploración e investigación y 18 meses para la concesión ${ }^{40}$;

40 En Andalucía vid la Ley 9/2001, de 12 de julio, por la que se establece el sentido del silencio administrativo y los plazos de determinados procedimientos como garantías procedimentales para los ciudadanos, regula expresamente el plazo de resolución de los permisos de exploración, 
le sigue Galicia ${ }^{41}$ con el plazo común de 12 meses para la tramitación de los títulos mineros y Valencia con el plazo común de 9 meses para los tres títulos mineros ${ }^{42}$; Aragón 8 meses ${ }^{43}$; Canarias ${ }^{44} 3$ meses para el permiso de exploración; permiso de investigación en terrenos francos y registrables 9 meses y en terrenos no francos ni registrables 5 meses y para la concesión derivada de un permiso de investigación 5 meses y concesión directa 10 meses seguida de Castilla La-Mancha que establece el plazo común de 6 meses en la Ley 7/2013, de 21 de noviembre, de adecuación de procedimientos administrativos y

investigación y concesión. Y además regula: autorización de proyectos de instalaciones mineras 18 meses desestimatorio; establecimiento de beneficios mineros 12 meses silencio desestimatorio. Regula expresamente el efecto desestimatorio pero no el plazo, por lo que se aplica el plazo supletorio de: autorización de voladura tipo en minería; ocupación temporal para permisos de exploración o de investigación y para concesiones de explotación de recursos de la sección C; declaración de utilidad pública de establecimientos de beneficios.

${ }^{41}$ Es la Ley $3 / 2008$, de 23 de mayo de Ordenación de la minería de Galicia la que establece el plazo común de 12 meses para resolver los procedimientos de otorgamiento de los permisos mineros de exploración, investigación y concesión. Por su parte, la ley 6/2001, de 29 de junio, de adecuación de la normativa de la Comunidad Autónoma de Galicia a la Ley 4/1999, de 13 de enero, de modificación de la Ley 30/1992, de 26 de noviembre, de régimen jurídico de las administraciones públicas y del procedimiento administrativo común reguladora de los procedimientos y efectos del silencio relaciona en el Anexo II los procedimientos con silencio negativo, pero sin establecer el plazo de resolución los mismos. Son, en lo que aquí importa con relación a los recursos de la Sección C y D: autorizaciones de agrupaciones o concentraciones mineras; autorizaciones de transmisión de derechos mineros; declaración de compatibilidad de explotaciones mineras; suspensión de trabajos mineros, aprobación de proyectos e instalaciones mineras, procedimientos de otorgamiento de demasías.

42 El Decreto valenciano 166/1994, de 19 de agosto, de adecuación a Ley 26 noviembre 1992 de Régimen jurídico de las Administraciones públicas y del procedimiento administrativo común establece el plazo común de 9 meses para la resolución de los permisos mineros y además regula: la autorización de instalaciones y actividades necesarias para explotaciones mineras y extractivas y de alumbramiento de agua 6 meses desestimatorio; instalación, ampliación, traslado, cambios de titularidad de establecimientos de beneficio de sustancias minerales 3 meses estimatorio.

${ }^{43}$ Aragón, la Ley 8/2001, de 31 de mayo, del Silencio Administrativo de Aragón además del plazo de los procedimientos de otorgamiento de los permisos de exploración, investigación y concesión (8 meses), regula también: la concentración de trabajos mineros; declaración de demasía; admisión definitiva de solicitud de derechos mineros 8 días; paralización de trabajos mineros; prórroga de concentración de trabajos mineros; prórroga de paralización de trabajos mineros; ampliación de recurso; prórroga de comienzo de labores mineras; prórroga de derechos mineros; autorización arrendamiento de derechos mineros; compatibilidad/Incompatibilidad de trabajos mineros; admisión a trámite de solicitud de derechos mineros; suspensión de labores mineras en caso de urgencia; disponibilidad de mineral; intrusión de labores mineras; aprobación de obras de control en caso de existir peligro de inundación sobre labores; concurso público de derechos mineros; creación de cotos mineros; aprobación de proyectos de instalaciones mineras nuevas o sus modificaciones 3 meses; aprobación de proyecto de escombrera, depósito de residuos, balsas y diques de estériles; autorización de suspensión y abandono de labores y otras en materia de seguridad minera como autorización de voladuras en todos los casos estableciendo el plazo de 3 meses de silencio negativo.

${ }^{44}$ En Canarias, véase el Decreto 164/1994, de 29 de julio (versión consolidada), que adapta los procedimientos administrativos de la Comunidad Autónoma a Ley 30/1992, de 26-11-1992, de Régimen Jurídico de las Administraciones Públicas y del Procedimiento Administrativo Común. También regula la constitución de cotos mineros 4 meses silencio negativo. 
reguladora del régimen general de la declaración responsable y comunicación previa.

Asimismo, la mayor parte de las CCAA que han regulado esta cuestión han optado por establecer un plazo único e igual para la tramitación de todos los títulos mineros de los recursos de las Secciones $C$ y $D$, opción que de una parte redunda en mayor seguridad jurídica pero que, sin embargo, no diferencia la mayor o menor intensidad y complejidad de la intervención administrativa requerida en cada uno de ellos, así como el grado de transformación del terreno que conlleva cada uno de los títulos mineros, así como su duración. En este sentido, Baleares (18 meses), Galicia (12 meses), Valencia (9 meses), Cantabria (8 meses) ${ }^{45}$ y Castilla La -Mancha (6 meses). Sólo algunas CCAA parecen haber llevado a cabo una reflexión en el sentido propuesto de atribuir un mayor plazo de resolución distinguiendo según el grado de intensidad de la intervención administrativa requerida acorde con la intensidad y plazo de la transformación del terreno y de la técnica minera exigida por los particulares en cada permiso minero estableciendo plazos más breves para la exploración y /o investigación, frente a la concesión de explotación: en este grupo Andalucía (12 meses) exploración e investigación y 18 meses para la concesión o Canarias (3 meses para la exploración), permiso de investigación en terrenos francos y registrables 9 meses no francos ni registrables 5 meses, concesión derivada de permiso de investigación 5 meses y para la concesión directa 10 meses. De manera

\footnotetext{
45 La Ley de Cantabria 5/2018, de 22 de noviembre, de Régimen Jurídico del Gobierno, de la Administración y del Sector Público Institucional de la Comunidad Autónoma de Cantabria regula de manera expresa el plazo de resolución del permiso investigación en 8 meses y el procedimiento sancionador en materia minera 1 año. Asimismo, entre los procedimientos con silencio negativo hace mención a los permisos de investigación, exploración y concesiones de explotación de recursos mineros sección $\mathrm{C}$ y $\mathrm{D}$, pero sin establecer su plazo, por lo que se rigen por el plazo legal supletorio. Hace también referencia entre los procedimientos con sentido negativo del silencio a: admisión a trámite de solicitud de derechos mineros; concentración, paralización y sus prórrogas de trabajos mineros; transmisión de derechos mineros; permisos de investigación, exploración y concesiones de explotación de recursos mineros sección $\mathrm{C}$ y $\mathrm{D}$; otorgamiento de una demasía minera a una concesión de explotación de recursos de las secciones C y D; ampliación del recurso; aprovechamiento de un nuevo recurso descubierto en una concesión de explotación; prórroga de comienzo de labores mineras; prórroga de vigencia de derechos mineros; autorización de la constitución de cotos mineros. reclasificación de una autorización de explotación en una concesión de explotación de recursos de la Sección C; autorización de cierre y abandono definitivo de labores; autorización de instalaciones de preparación, concentración o beneficio de los recursos comprendidos en el ámbito de la Ley de Minas.
} 
paradógica, Asturias ${ }^{46}$ sigue justo el criterio opuesto, estableciendo 6 meses para los permisos de exploración e investigación y 60 días para la resolución de la concesión de explotación.

Varias CCAA no regulan el plazo de resolución de los procedimientos de otorgamiento de los títulos mineros de su competencia, por lo que en defecto de regulación expresa hay que aplicar el plazo legal supletorio especial de la legislación minera estatal y, en su defecto, el plazo supletorio legal común de los tres meses establecido en el art. 21.3 de la Ley 39/2015, de 1 de octubre, de Procedimiento Administrativo Común de las Administraciones públicas que proclama: "Cuando las normas reguladoras de los procedimientos no fijen el plazo máximo, éste será de tres meses". En este grupo se encuentran Cataluña ${ }^{47}$, Extremadura ${ }^{48}$, Madrid ${ }^{49}$ y Navarra ${ }^{50}$.

Por lo que respecta al plazo legal supletorio especial, es decir, el propio de la legislación minera hay que tener en cuenta el art. Noveno uno de la Ley 54/1980, 5 de noviembre, de modificación de la Ley de Minas, con especial atención a los recursos minerales energéticos que para el permiso de investigación establece el plazo de 8 meses de resolución desde que se declare definitivamente admitida la solicitud. Este precepto modificó el plazo previsto en el art. 71.5 del RD 2857/1978, de 25 de agosto, por el que se aprueba el Reglamento General para el régimen de la minería (RGRM) que era de 6 meses a contar de la fecha en que se declare definitivamente admitida la solicitud.

\footnotetext{
46 El Decreto 67/2002, de 16 de mayo, por el que se aprueban las normas relativas a procedimientos administrativos de la Administración del Principado de Asturias establece el plazo de resolución de los permisos de exploración, investigación (6 meses), y concesión (60 días).

${ }^{47}$ La Ley 23/2002, de 18 de noviembre, de Adecuación de procedimientos administrativos en relación con el régimen de silencio administrativo y el plazo de resolución y notificación, y primera modificación de los artículos 81, 82 y 83 de la Ley 13/1989, de 14-12-1989, de organización, procedimiento y régimen jurídico de la Administración de la Generalidad de Cataluña no regula los procedimientos relativos a títulos mineros.

${ }^{48}$ La Ley 1/2002, de 28 de febrero, del Gobierno y Administración de Extremadura no regula los permisos ni otros procedimientos con relación a los recursos mineros de la Sección C y D.

${ }^{49}$ La Ley $1 / 2001$, de 29 de marzo, por la que se establece la duración máxima y el régimen de silencio administrativo de determinados procedimientos de la Comuidad de Madrid, no regula el plazo de resolución de los procedimientos mineros, por lo que será de aplicación el plazo legal supletorio.

50 La Ley Foral 11/2019, de 11 de marzo, de la Administración de la Comunidad Foral de Navarra y del Sector Público Institucional Foral los Anexos no regulan ningún procedimiento relativo a permisos mineros.
} 
Por lo que repecta a la concesión directa o derivada nada dice la LMi sobre el plazo de resolución del procedimiento, mas el art. 85.1 RGRM se limita señalar que: "Las solicitudes de concesión directa de explotación o derivadas de permisos de exploración, se tramitarán en la misma forma que las de los permisos de investigación, siendo aplicables las disposiciones del capítulo III del presente título, con las particularidades que correspondan a esta clase de solicitudes (...)", por lo que hay que entender aplicable el mismo plazo de 8 meses establecido para la resolución de los permisos de investigación en el citado art. Noveno de la Ley 54/1980.

Por último, ni la LMi ni su reglamento regulan el plazo de resolución del procedimiento de otorgamiento del permiso de exploración, por lo que en este caso, a falta de regulación autonómica expresa, será de aplicación el plazo legal supletorio común de los 3 meses de la LPAC.

Por otra parte, nos encontramos con CCAA que igual que en el caso anterior no regulan los procedimientos relativos a la minería, por tanto carecen en su derecho propio de plazo específico de resolución de los procedimientos mineros de su competencia. Sin embargo, en sede electrónica establecen el procedimiento de tramitación indicando, sin apoyo en norma autonómica alguna, un plazo de duración que tampoco se acomoda al plazo legal supletorio especial o común de la legislación estatal. En esta situación se encuentran: Castilla y León, cuyo Decreto 183/1994, de 25 de agosto, por el que se determinan los plazos de resolución de los procedimientos administrativos de la Administración de Castilla y León, y los efectos estimatorios o desestimatorios que la falta de resolución expresa produzca, sigue en vigor. Sin embargo, la sede electrónica de Castilla y León sin indicar el fundamento normativo dispone para la tramitación de los permisos de exploración e investigación de recursos mineros de las Secciones C) y D) 6 meses, y para la concesión de explotación de recursos mineros de las referidas Secciones 6 meses $^{51}$, plazos que no se acomodan a la legislación minera estatal supletoria; Murcia, cuya Ley 1/2002, de 20 de marzo, de Adecuación de los Procedimientos de la Administración

51 Permiso de exploración de recursos de la sección C) y sección D) de la Ley de minas (código 1024)

https://www.tramitacastillayleon.jcyl.es/web/jcyl/AdministracionElectronica/es/Plantilla100Detalle /1251181050732/Tramite/1284627436533/Tramite; 
Regional de Murcia a la Ley 30/1992, de 26 de noviembre, de Régimen Jurídico de las Administraciones Públicas y del Procedimiento Administrativo Común no regula nada relativo a los recursos mineros de las Secciones $C$ y $D$. Sin embargo, en su sede electrónica se indica para el permiso de exploración el plazo de 6 meses $^{52}$ no previsto en la norma estatal y para el permiso de investigación 8 meses $^{53}$, y para la concesión directa o derivada de explotación también el plazo de 8 meses $^{54}$ que sí se corresponde con el plazo de la legislación minera estatal. En el País Vasco tampoco hay norma reguladora de los procedimientos relativos a los permisos mineros, mas en sede electrónica se dispone con relación al procedimiento para la obtención de autorizaciones 0 concesiones de aprovechamientos de recursos de las secciones A) B) C) y D) y para sus modificaciones 6 meses, plazo que tampoco se acompasa al plazo legal supletorio especial de la legislación estatal minera ${ }^{55}$. Por el contrario, en La Rioja ante la ausencia de norma propio reguladora de estos procedimientos en sede electrónica se aplican acertadamente los plazos legales supletorios comunes y especiales: para los permisos de exploración Secciones C) o D) se dispone el plazo de 3 meses $^{56}$, para los permisos de investigación Secciones C) ० D) 8 meses desde la admisión definitiva de la solicitud ${ }^{57}$ y para la concesión directa de explotación de recursos 8 meses $^{58}$.

En otro orden de consideraciones, se observa una generalizada falta de regulación expresa del plazo de resolución de procedimientos tan comunes y normales como las solicitudes de prórrogas de los títulos mineros, donde

\footnotetext{
52 Permiso de exploración de recursos de la sección C) y sección D) de la Ley de minas (código 1024)

https://sede.carm.es/web/pagina?IDCONTENIDO=1024\&IDTIPO=240\&RASTRO=c $\$ \mathrm{~m} 40288$

53 Permisos de investigación de recursos de la sección $\mathrm{C}$ ) y sección $\mathrm{D}$ ) de la Ley de minas (código 1026)

https://sede.carm.es/web/pagina?IDCONTENIDO=1026\&IDTIPO=240\&RASTRO=c $\$ \mathrm{~m} 40288$

${ }^{54}$ Concesión directa o derivada de explotación de recursos de la sección C) y sección D) de la Ley de minas (código 1054) https://sede.carm.es/web/pagina?IDCONTENIDO=1054\&IDTIPO=240\&RASTRO=c $\$ \mathrm{~m} 40288$ 55 en https://www.euskadi.eus/web01tramite/es/contenidos/autorizacion/mc_ord_aut_aprove_recursos_sec/es_mc/autorizacion_apro vechamiento_recursos_secc_a_b_c_d.html

$56 \mathrm{https}: / / \mathrm{www}$.larioja.org/oficina-electronica/es?web=000\&proc $=13016$

$57 \mathrm{https}: / /$ www.larioja.org/oficina-electronica/es? $w e b=\& p r o c=13027 \#$ tab4

$58 \mathrm{https}: / /$ www.larioja.org/oficina-electronica/es?web $=000 \&$ proc $=13015$. También se hace referencia expresa a caducidad de la explotación de recursos mineros a instancia del interesado indicando el plazo de 3 meses de silencio negativo la https://www.larioja.org/oficinaelectronica/es? web $=000 \&$ proc $=13030$
} 
procede un replanteamiento para encarar una regulación más ágil, en la que se reduzca al máximo la discrecionalidad administrativa. Por lo demás, el plazo de resolución de las prórrogas debe ser coherente con el plazo de duración del propio permiso cuya prórroga se solicita. En este sentido, llama la atención que Andalucía y Baleares que sí regulan esta cuestión, establecezcan por ejemplo en 6 meses el plazo de resolución de la prórroga del permiso de exploración que tiene una vigencia de 1 año según la LMi. Se da el contrasentido que para la solicitud del permiso se aplica el plazo legal supletorio común de resolución de 3 meses y en cambio para la solicitud de la prórroga se establece un plazo mayor, de 6 meses. Igualmente, sólo regula el plazo de resolución de las autorizaciones de transmisión de derechos mineros Aragón, disponiendo el plazo de 3 meses para su resolución, plazo legal autonómico que viene a coincidir con el plazo legal supletorio vigente en el resto de las CCAA ex art. 21.2 LPAC.

Mención aparte merecen la caducidad y el procedimiento sancionador en materia minera, pues no sólo hay una mayoritaria falta de regulación del plazo de resolución de estos procedimientos, sino que como un prius planea la confusión existente entorno al equívoco concepto de caducidad ${ }^{59}$ de la legislación minera (arts 83-88 LMi y 106 a 112 RGM) toda vez que se refiere a la extinción anticipada del título por diferentes causas: de una parte, aquéllas en las que no no hay incumplimiento alguno del titular del permiso tales como la renuncia voluntaria, el agotamiento del recurso, o la expiración del plazo por los que fueron otorgados $\mathrm{o}$, en su caso, las prórrogas concedidas, y de otra parte, causas debidas al incumplimiento del titular del permiso y en la que la Administración ejerce la potestad sancionadora ante incumplimientos de la normativa minera tipificadas como infracción administrativa. Se impone pues deslindar claramente entre las causas de caducidad no constitutivas de infracción y regular su plazo repensando si es suficiente el plazo supetorio legal común de 3 meses de la Ley de Procedimiento Administrativo Común para cualesquiera que sean las causas $y$, de otra parte, ordenar el plazo de resolución de los procedimientos sancionadores en materia de minería ${ }^{60}$.

59 Véase sobre esta cuestión QUINTANA LÓPEZ, T. "Viejos y nuevos poblemas de a concesión minera", Revista juríica de Castilla y León, № 18, 2009, págs. 58 a 71.

${ }^{60} \mathrm{El}$ art. 122 de la LMi en su número 3 tipifica como infracción leve el incumplimiento de cualquier obligación derivada de la presente Ley y las disposiciones reglamentarias de aplicación, del Plan 
Como es sabido, la Ley de Procedimiento Administrativo Común de las Administraciones Públicas de 2015 ha derogado el Real Decreto 1398/1993, de 4 de agosto, por el que se aprueba el Reglamento del Procedimiento para el ejercicio de la potestad sancionadora, cuyo art. 20.6 establecía el plazo de 6 meses para la resolución y notificación del mismo, pasado el cual se produce la caducidad. La LPAC al no regular un plazo específico para el procedimiento sancionador se sujeta también al plazo supletorio legal general de los 3 meses. Sin embargo, hay que tener en cuenta que el art. 121.8 LMi preceptúa que "EI procedimiento sancionador caducará al año de su iniciación"61, que constituye el plazo legal supletorio para los procedimientos sancionadores relativos a la actividad extractiva. Regulan el plazo resolución del procedimiento sancionador en materia minera expresamente sólo Balerares (12 meses), Cantabria (1 año) y Galicia (12 meses) en el mismo sentido que la legislación estatal.

En definitiva, para una buena regulación de los procedimientos mineros se impone una reflexión sobre el plazo legal de tramitación de los procedimientos mineros, con mayor transparencia y facilidad de acceso a la información relativa a la duración de los mismos, pues en ocasiones hay que llevar a cabo un arduo rastreo para averiguar si no hay regulación expresa autonómica legal o reglamentaria en cuyo caso se aplica el plazo legal supletorio de los tres meses u 8 meses (permiso de investigación) o, si por el contrario, existe esa regulación expresa que en ocasiones se halla en anexos de normas sobre el plazo y sentido del silencio de los procedimientos de competencia autonómica (Decretos y/o Leyes de adaptación a la Ley 30/1992 y modificaciones ulteriores) como en Leyes generales sobre la Administración difíciles de encontrar incluso para un especialista.

La pregunta es ¿está justificada tal heterogeneidad de plazos? ¿resulta fácil y sencillo acceder a la información y fundamentación legal de los tiempos de tramitación de los permisos mineros? Como ya se ha manifestado, creemos que

de Labores aprobado o de una prescripción impuesta para el cumplimiento de esta Ley por el órgano competente, siempre que no esté tipificada en los apartados 1 como infracción muy grave o 2 grave. Asimismo, en el número 4 se ordena que "Las infracciones a los preceptos de esta Ley, sin perjuicio de la declaración de caducidad o suspensión de los trabajos cuando ello proceda, se sancionarán en la forma siguiente (...).

${ }^{61}$ Art. redactado por la disposición adicional primera de la Ley 12/2007, de 2 de julio, por la que se modifica la Ley 34/1998, de 7 de octubre, del Sector de Hidrocarburos. 
la respuesta es negativa. A nuestro juicio, se impone la actualización de la regulación del factor tiempo en estos procedimientos tras una reflexión que tenga en cuenta la importancia de la actividad minera para la economía de la Comunidad Autónoma, la complejidad de los procedimientos y sus posibilidades de simplificación, los medios y recursos materiales y humanos a disposición de la Administración y en coherencia con su política económica y ambiental regular el factor tiempo para acercar el plazo legal al real de resolución de los procedimientos mineros.

Si una Comunidad Autónoma quiere fomentar una actividad minera sostenible social y medioambientalmente debe hacer un análisis de la tramitación de los procedimientos, su complejidad, duplicidades, grado de coordinación administrativa, participación de los interesados, reducción de la discrecionalidad, así como incrementar la eficacia de la Administración en su gestión, resultando un indicador relevante el tiempo de respuesta que contribuya a incentivar la inversión y despejar la inseguridad jurídica. Sin ese previo análisis para aportar soluciones de mejora regulatoria -lo que incluye reforzar los medios personales y materiales (administración electrónica y ventanilla única)-, iniciativas de fomento de proyectos mineros que conlleven una reducción del plazo actual normativamente establecido de tramitación de los procedimientos administrativos, estarán abocadas a tener escasa o nula eficacia. En este sentido, podemos citar a modo de ejemplo el Decreto-ley 4/2019, de 10 de diciembre, para el fomento de iniciativas económicas mediante la agilización y simplificación administrativas en la tramitación de proyectos y su declaración de interés estratégico para Andalucía, para la creación de una unidad aceleradora de proyectos de interés estratégico y por el que se modifica la Ley 1/1994, de 11 de enero, de Ordenación del Territorio de la Comunidad Autónoma de Andalucía, y la Ley 7/2002, de 17 de diciembre, de Ordenación Urbanística de Andalucía, mediante el que se pretende incentivar la inversión productiva en la región y en cuya virtud un proyecto minero que cumpla con los requisitos del art. 3 puede ser declarado de interés estratégico para la Comunidad Autónoma. Dicha declaración conlleva según el art. 7.2 en lo que aquí importa una reducción a la mitad de los plazos administrativos, salvo los relativos a la presentación de solicitudes y recursos, a los procedimientos de concurrencia competitiva y medio 
ambiente. Asimismo, se reducirá a la mitad el plazo máximo para resolver y notificar. No obstante, ad cautelam, se prevé de manera excepcional en el apartado 2.3 del art. 7 la ampliación del plazo para resolver y notificar con el límite de que en ningún caso podrá superar el plazo para resolver y notificar establecido con carácter general en la norma reguladora del procedimiento.

\section{CONCLUSIÓN}

La importancia de la minería como sector estratégico impone la necesidad de mejorar el marco jurídico de las actividades extractivas a nivel europeo y de los Estados miembros que asegure el abastecimiento de materias primas al tiempo que permita que la minería juegue un papel clave en la economía circular, la implantación de las tecnologías limpias y la lucha contra el cambio climático.

La República de Irlanda ocupa una posición privilegiada en las encuestas anuales del Instituto Fraser sobre empresas mineras por disponer de un entorno regulatorio que incentiva la inversión y es respetuoso con el medio ambiente. Esta circunstancia justifica el análisis del régimen de la minería en Irlanda, como un buen modelo de Derecho comparado de cuyas características y fortalezas se puede aprender.

La República de Irlanda ha hecho un esfuerzo por dotarse de una legislación minera fácilmente comprensible, dotada de seguridad jurídica y con directrices ambientales sencillas. Además, ha sido objeto de actualizaciones periódicas que han culminada en la Minerals Development Act de 2017. El apoyo a la actividad minera se traduce en una regulación que fomenta y favorece la exploración.

El régimen de propiedad de los minerales en la República de Irlanda es mixto y complejo, sin embargo, resulta ser un factor "neutro" que no incide en la calidad del marco regulatorio de la actividad extractiva, en indicadores tales como comprensión, coherencia, seguridad jurídica y tiempos de respuesta de los procedimientos.

Se trata de un marco jurídico flexible, con una gran coordinación administrativa donde no hay solapamientos competenciales. El Ministro de Comunicaciones, Acción Climática y Medio Ambiente es el órgano sustantivo que actúa como ventanilla única. Esto hace que los procedimientos sean eficientes también 
desde la perspectiva del factor tiempo y que las tasas de éxito en la obtención de los permisos mineros sean muy altas. No se conocen casos judiciales importantes en Irlanda, lo que indica que la vía judicial no se utiliza con frecuencia para resolver disputas.

En España hay un amplio margen de mejora regulatoria de los procedimientos de otorgamiento de los permisos mineros afectados por duplicidades, solapamientos competenciales y criterios interpretativos dispares que inciden negativamente en su tramitación. En particular, centrados en el plazo de resolución de los procedimientos de otorgamiento de los permisos mineros podemos concluir de una parte que no es fácil y sencillo conocer cuáles son esos plazos debido a la diversidad de normas autonómicas en las que se pueden regular: Leyes de minas autonómicas, sólo promulgadas en dos casos, la Ley 10/2014, de 1 de octubre, de ordenación minera de las Illes Balears y la Ley $3 / 2008$, de 23 de mayo, de ordenación de la minería de Galicia y reglamentos o leyes que regulan los plazos de resolución de los procedimientos de competencia autonómica. En defecto de regulación autonómica propia, serán de aplicación los plazos supletorios especiales de la LMi y de su Reglamento y, en su defecto, el plazo supletorio común de los 3 meses de la LPAC. De otra parte, hemos comprobado la existencia de una gran heterogeneidad de plazos en las CCAA, carentes de justificación. Es pues necesario repensar el modelo.

Por lo demás, es indiferente el régimen de titularidad de las minas, lo que importa es que los poderes de regulación de la Administración sobre la actividad minera y su ejercicio se desarrollen en un marco regulatorio coherente con el conjunto de las políticas públicas adoptadas, coordinado entre todas las Administraciones implicadas, comprensible, fundado en los principios de sosteniblidad y de la economía circular, eficaz, que reduzca la discrecionalidad administrativa, elimine requisitos duplicados, innecesarios y desproporcionados, al tiempo que pueda ser necesario crear otros nuevos justificados en intereses dignos de tutela tales como la participación de la comunidad local a través de la licencia social y, en particular, en el diseño de los planes de restauración. En definitiva, incrementar la calidad y seguridad jurídica del marco regulatorio del otorgamiento de los permisos mineros. Sin duda, el factor tiempo es una pieza importante del sistema. 


\section{BIBILOGRAFÍA}

BANCO MUNDIAL The Growing Role of Minerals and Metals for a Low Carbon Future, Washington de junio 2017

Casado Casado, L.: "Actividades extractivas y espacios naturales protegidos: la Red Natura 2000", en Minería extractiva, planificación territorial y urbanismo, MONTOYA MARTíN, E. (Dir), Tirant lo Blanch, Valencia págs. 26-102.

COMISIÓN EUROPEA "Legal framework for mineral extraction and permitting procedures for exploration and exploitation in the EU', Final report, Dirección General de Mercado Interior, Industria, Emprendimiento y Pymes Comisión Europea, Minpol, mayo 2017

Doménech Pascual, G.: "Por qué y cómo hacer análisis económico del Derecho", RAP, 195, 2014, págs. 99-133

Green, K.P. - Jackson, T.: Permit Times for Mining Exploration in 2016, Fraser Institut, February 28, 2017

Legoux, P.: "Legislaciones mineras de los Estados miembros de la Comunidad Económica Europea", RAP, № 113, 1987, págs. 365-398

Montoya Martín, E.: "Presentación" en Minería extractiva, planificación territorial y urbanismo, Montoya Martín, E. (Dir.) Tirant lo Blanch Valencia 2020

Quintana López, T.: "Viejos y nuevos poblemas de a concesión minera", Revista juríca de Castilla y León, no 18, 2009, págs. 13-73

Quintana López, T.: Concesión de minas y protección del medio ambiente, Tirant lo Blanch, Valencia, 2013

Stedman, A.- Green, K.P: Permit Times for Mining Exploration in 2017 Fraser Institut, 2018

Stedman, A.- Green, KP.: Annual Survey of Mining Companies: 2017, 22 Febrero 2018

Stedman, A., Yunis, J.- Aliakbari, E.: Annual Survey of Mining Companies, 2019, 25 febrero de 2020

Vergara Blanco, A. Principios y Sistema del Derecho minero. Estudio histórico dogmático, Edit. jurídica de Chile, 1992. 